\title{
The hydraulic test system based on virtual instrument technology
}

\author{
Sun Peng ${ }^{1, a^{*}}$, Wang Hongwei ${ }^{1, b}$,Ding Zeping ${ }^{2, b}, \mathrm{He} \mathrm{Nan}^{3, \mathrm{~b}}$, Yin Dawei ${ }^{1, \mathrm{c}}$, \\ Yang Yingjun ${ }^{1, d}$
}

1.Department of Aircraft and Dynamics, The Aviation University of Air Force,Changchun 130022, China

2.The Unit 74, NO.95852 troops of the Chinese people's liberation army , Xiaogan 432100,China

3. NO.95926 troops of the Chinese people's liberation army, Changchun 130022,China

a.rocy527@163.com,b.whw1001@126.com,c.efforman0434@163.com,d.yyjmajor@163.com

Keywords: Hydraulic test ; Data acquisition and processing; The module design.

Abstract. Based on CAT (hydraulic computer aided test technology), by use of multiple sensors gathering experimental signals, the testing platform develops performance testing work to axial piston pump on the hydraulic controlling platform. Based on digital computer and LabVIEW graphic development platform from NI corporation in America, the testing system realizes work transition and real time monitoring of state and performance of axial piston pump, which has the function of data acquisition, processing, monitoring, and report printing and filing. Furthermore, according to module design thread on software development, the testing system acquires greatly programming efficiency and system operation velocity.

\section{Introduction}

Hydraulic system has been widely used in industrial control, mechanical, aerospace and other fields. Hydraulic pump of Hydraulic system as dynamic element, is the heart of the hydraulic system, its performance directly influences the whole performance of the hydraulic system. Therefore, the hydraulic system of hydraulic pump system of important hydraulic components such as testing has very important significance.

Hydraulic CAT (Computer Aided Test)system based on virtual instrument is compared with the conventional hydraulic system mainly has the following advantages: improve the test accuracy, improve the testing speed, enhance the capacity of data processing, the convenient user use.

\section{The whole design of Hydraulic test platform}

In order to accurately test and record the change of the hydraulic system working parameters and condition, diagnosis of hydraulic system, hydraulic components performance test, using the virtual instrument technology, we design a hydraulic testing platform, is used to accurately monitor and control the working state of hydraulic platform and work performance. This platform has the versatility, real-time display accurate, reliable operation, the characteristics of a broad prospect of application and development.

Test platform on the basis of the hydraulic control platform, through the erection of filter circuit, connected dual channel acquisition card, the hydraulic test bed and filter circuit, acquisition card and computer is an organic whole repeatedly.This test system architecture is divided into five parts: the signal conditioning circuit, data acquisition card, data processing circuit and a control computer.Main task is to transform the sensors to collect digital/analog signal after eyelid circuit amplification, the incoming acquisition card, data processing circuit for processing the coma to control in the computer display.

No-load verification test is determined by measuring the displacement of axial piston pump under different set speed no-load steady working condition when the flow rate $\left(q_{v 2, \mathrm{e}}\right)$ and rotational speed 
$\mathrm{n}$, and then through the formula (1) calculate the light emissions, if light row quantity within 95\% $110 \%$ of nominal displacement, the displacement of axial piston pump for qualified.

$$
V_{i}=1000 \times \frac{N \times\left(\sum_{j=1}^{N} n_{j} q_{v 2, e_{j}}\right)-\left(\sum_{j=1}^{N} n_{j}\right)\left(\sum_{j=1}^{N} q_{v 2, e_{j}}\right)}{N \times\left(\sum_{j=1}^{N} n_{j}^{2}\right)-\left(\sum_{j=1}^{N} n_{j}\right)^{2}}
$$

In the type,$V_{i}$ stands for Light emission, unit is $\mathrm{ml} / \mathrm{r}$; $\mathrm{n}$ stands for the actual speed, unit is r/min; $N$ stands for Speed test file number; $q_{v 2, \mathrm{e}}$ stands for Effective output flow, unit is $\mathrm{L} / \mathrm{min}$ 。

\section{The hydraulic testing platform software design}

A device driver is the basis of virtual instrument system, is the application and the hardware interface of the bridge and the link.Most of the driver software has these functions, but must ensure that the driver is not only able to get and send data from the data acquisition board, to the calibration data sampling rate.At the front desk to deal with the data at the same time, to collect data in the background;Can perform several functions at the same time;With multiple board integration capabilities;To ensure seamless combination and signal conditioning accessories.

The main program mainly adopts the object-oriented method to write, first create a project, will be useful function module VI, pictures, interface program and sound files to join in.To be carried out in accordance with the project of each classification module to write, so write to late debugging object-oriented program changes and subsequent comments, beautification, and extend the functionality.

Software part of the main program design according to the software modular thought, is the whole software system is divided into many small independent modules.Independent small module by module interface between links, in this way, the module internal data structures are protected, there is no interference between modules, according to the function modular structures.This software system is mainly including parameter input module, software module, information collection module, data processing module, etc.Parameter input module provides the dialogue interface between the user and the software part, software part through parameter input module user instruction and test initial conditions, the critical conditions, such as the necessary parameters.Software control module according to the parameter input module for user instructions, multifunctional test-bed control hydraulic system work.Information acquisition module to obtain the output parameters of all kinds of test instruments and meters, and will be for temporary storage of data.Data processing module to invoke the temporary data information collection module, and to the corresponding processing (such as automatic graphing, print, save, real-time display and detection), improve the test accuracy and efficiency, and facilitate the user always grasp the test condition.Some cases (such as the test pressure is too large or working conditions vary considerably with the user set), data processing module of data and information feedback to the control system, according to the relevant information to adjust test bench work status, so as to adapt to a variety of test requirements and protect the normal work of the test-bed and safety.

In accordance with the method of object-oriented program, will be huge disassembled into several main program subroutine, the main program only play the role of call big quantum program, each subroutine is strictly independent relationship between formation of high cohesion and low coupling relationship.

\section{Pressure flow characteristic of data processing and result analysis}

After the completion of integrated hydraulic test rig, the test bench for the part of the performance verification.Driven by hydraulic components, which were tested on the actual conditions, failed to fully implement the test bench for all performance testing, but the actual testing components have 
points for each test parameter and each test system working status is verified, and test measurement data is consistent with the actual tested components. This paper introduced the performance test only for the following components: hydraulic pump and proportional pressure reducing valve, hydraulic tank.

In axial piston pump rated speed $2200 \mathrm{r} / \mathrm{min}$ of $40 \%, 50 \%, 60 \%, 70 \%, 80 \%, 90 \%$ and $100 \%$ under the set speed of measuring the light output flow, averaged three times.Calculated by displacement formula of the axial piston pump light displacement, and the nominal displacement axial piston pump, measured no-load row value is very close to the axial column the nominal capacity of the pump.If light row quantity within $95 \% \sim 110 \%$ of nominal displacement, the axial plunger pump displacement for qualified.

According to the test method and the actual technical parameters of axial piston pump, respectively in axial piston pump rated speed $2200 \mathrm{r} / \mathrm{min}$ of $40 \%, 50 \%, 60 \%, 70 \%, 80 \%, 90 \%$ and $100 \%$ of the set speed and maximum displacement under its light output and the actual speed of flow measurement. The test data as shown in table 1.

Table 1 Displacement experiment data tables

\begin{tabular}{|c|c|c|c|c|c|c|}
\hline $\begin{array}{c}\text { Speed } \\
\text { measuring } \\
\text { gear ratio }\end{array}$ & \multicolumn{3}{|c|}{ Output flow (L/min) } & \multicolumn{3}{c|}{ rap(r/min) } \\
\hline $40 \%$ & 96.8 & 96.8 & 96.7 & 880 & 880 & 880 \\
\hline $50 \%$ & 123.1 & 123.2 & 123.1 & 1100 & 1100 & 1100 \\
\hline $60 \%$ & 149.4 & 149.3 & 149.4 & 1320 & 1320 & 1320 \\
\hline $70 \%$ & 174.3 & 174.4 & 174.4 & 1540 & 1540 & 1540 \\
\hline $80 \%$ & 198.3 & 198.1 & 198.2 & 1760 & 1760 & 1760 \\
\hline $90 \%$ & 221.2 & 220.7 & 221.1 & 1980 & 1980 & 1980 \\
\hline $100 \%$ & 245.7 & 246.1 & 246 & 2200 & 2200 & 2200 \\
\hline
\end{tabular}

To the average of data and calculation, the axial plunger pump light emissions of $112.3 \mathrm{ml} / \mathrm{r}$, and the axial plunger pump nominal capacity is $112 \mathrm{ml} / \mathrm{r}$, measured no-load discharge value is very close to nominal displacement axial piston pump. Thus, the test system has the correct displacement verification experiment was carried out.

Negative flow control methods on hydraulic pump has been widely used in the negative flow control pressure is zero, the hydraulic pump is in a state of maximum displacement, maximum output flow.With the increase of negative flow control pressure, hydraulic pump of the swash plate Angle decreases, the output flow rate is decreased. When the negative flow control pressure exceeds a certain value and continue to rise, due to the limitation of the minimum limit screw, the swash plate Angle of the hydraulic pump reaches the minimum value, so the hydraulic pump output flow rate decreases, and no longer but keep minimum flow output.

In the speed of $200 \mathrm{r} / \mathrm{min}$, no-load, under pressure to $0.2 \mathrm{MPa}$ for interval, on the axial plunger pump from 0 to $4 \mathrm{MPa}$ increased and from 4 to $0 \mathrm{MPa}$ to gradually reduce the pressure of negative flow control, and record different negative flow control under the pressure of output flow value, get the test curve is shown in figure 1.

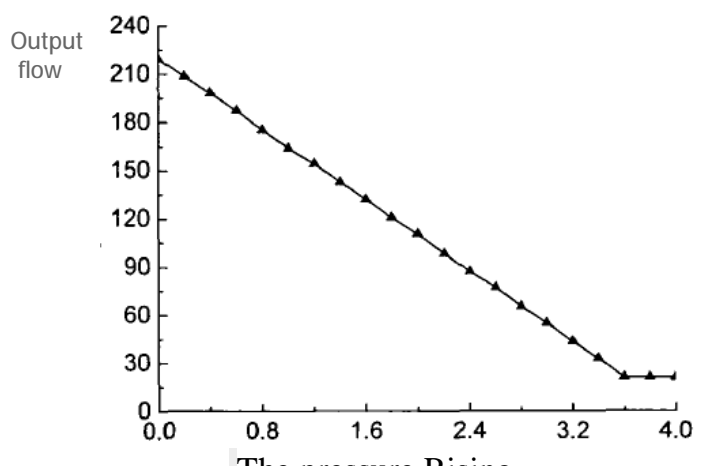

a. The pressure Rising

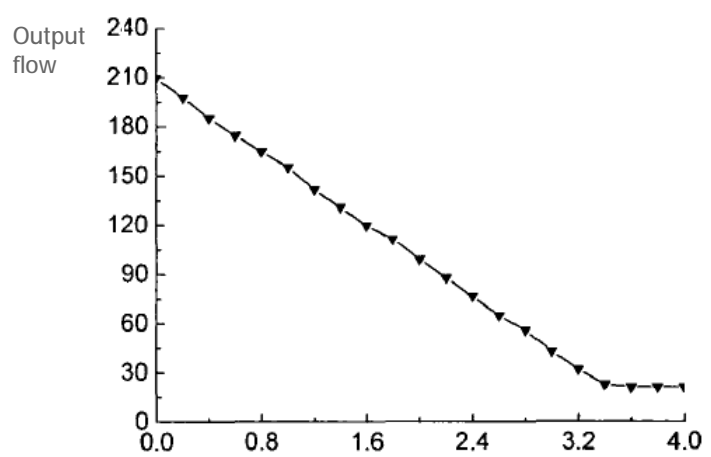

b. The pressure Reduce curve

Figure 1 The $p$-q curve o fTest the negative flow 
From negative flow control pressure flow test curve can be seen, in a negative flow control pressure is zero, the maximum displacement axial piston pump, which is $112 \mathrm{ml} / \mathrm{r}$, but the axial plunger pump output flow theory did not achieve the output flow $2241 / \mathrm{min}$, this is caused by the leakage of hydraulic pump are inevitable, as the normal phenomenon. When the negative flow control pressure is gradually increasing from 0 to $3.6 \mathrm{MPa}$, the swash plate Angle of the axial piston pump gradually decreases, and thus the output flow into a gradual decline. When the negative flow control pressure and more than $3.6 \mathrm{MPa}$. The variable axial piston pump piston and minimum limit screw contact, swash plate Angle reaches the minimum value, minimum displacement axial piston pump, and the axial plunger pump output minimum flow and constant.

By contrast, found that the plunger pump negative flow control pressure flow test curve change trend in line with the trend of the schematic diagram is shown in.Therefore concluded that the test result is correct.

\section{Summary}

The test data is correct by experimental verification system, the axial plunger pump output flow and output power and volume efficiency trend along with the change of rotating speed axial plunger pump performance test standard given in the axial plunger pump output flow and output power and volume efficiency trend along with the change of rotating speed.

The signal output and data acquisition system based on virtual instrument method is simple, reliable, applicable, can be achieved under the simulation environment to drive the embedded computer system run and collect its output signal, which laid a foundation for embedded software testing. Using virtual instrument to realize the software instead of hardware at the same time, avoid the use of a large number of special test equipment, saving the cost and improve the efficiency, achieved good effect.

\section{References}

[1] RuanJiZhen. LabVIEW and I - a NI engineer ten years programming experience. Beijing university of aeronautics and astronautics press. 2010

[2] Jon Conway, Steve Watts. A Software Engineering Approach to the LabVIEW. Tsinghua university press. 2006

[3] Zhou Lei. Variable plunger pump performance test system developed. Master thesis, zhejiang university. 2008

[4] Mr Yang. Hydraulic pump/motor performance testing system based on virtual instrument research. Master thesis of yanshan university. 2006

[5] Liu Hanbin. High finale to the plunger pump performance test system. Master thesis of zhejiang university. 2010

[6] Hong-liang sun, Li-hua Qiu, Zhan-lin Wang. Aircraft hydraulic pump computer-aided test system. Journal of instrument volume 27, 2006

[7] Ren Lujuan Han Yan. The data acquisition system based on LabVIEW and PCI - 5124 design.

Electronic design engineering volume 18, 2010 